Citation: Vaidya G. et al. (2018)

"Effects of Beta Blockers and

ACE Inhibitors after Left

Ventricular Assist Device

Implantation".

The VAD Journal, 4. doi: https://doi.org/10.13023/vad.2018 .09

Editor-in-Chief: Maya Guglin, University of Kentucky

Received: August 9, 2018

Accepted: September 6, 2018

Published: September 7, 2018

(C) 2018 The Author(s). This is an open access article published under the terms of the Creative Commons Attribution-

NonCommercial 4.0 International License

(https://creativecommons.org/lice nses/by-nc/4.0/), which permits unrestricted non-commercial use, distribution, and reproduction in any medium, provided that the original author(s) and the

publication source are credited.

Funding: Supported (in part) by an Alpha Omega Alpha

Postgraduate Award (Gaurang

Vaidya)

Competing interests: Not applicable
Peer-Reviewed Original Research

\section{Effects of Beta Blockers and ACE Inhibitors after Left Ventricular Assist Device Implantation}

\section{Gaurang Vaidya ${ }^{1}$, Emma Birks ${ }^{1}$, Jessica Pillarella ${ }^{1}$, Benjamin Salgado', Rajakrishnan Vijayakrishnan ${ }^{1}$, Andrew Lenneman ${ }^{1}$, Mark Slaughter ${ }^{1}$, Dmitry Abramov ${ }^{2}$}

*Corresponding author:gaurang2489@gmail.com

${ }^{1}$ University of Louisville

${ }^{2}$ Loma Linda University Medical Center, Loma Linda, CA

\section{Abstract}

\section{Background}

While Beta blockers (BB) and Angiotensin converting enzyme inhibitors/Angiotensin receptor blockers (ACEinh/ARB) are important components in advanced heart failure (HF) therapy, their use after left ventricular assist device (LVAD) implantation remains controversial. Concern has been raised about possible adverse effects of $\mathrm{BB}$ on right ventricular (RV) function while tolerance and efficacy/outcome data for ACEinh are lacking. This study aimed to characterize the use of medical therapy post-LVAD implantation and to evaluate its safety and efficacy.

\section{Methods}

Demographic, clinical and echocardiographic variables of patients implanted with a continuous-flow LVAD between 2012 and 2015 at a single center were retrospectively reviewed. Mortality and HF hospitalizations were followed from 618 months' post-implant.

\section{Results}

Of a total of 98 patients, the mean age was 57 years, $81 \%$ were men and $61 \%$ had ischemic disease. While the use of diuretics decreased considerably post LVAD, 
over $50 \%$ continued to require diuretics. At 6 th month post-implantation, $73 \%$ of patients were on BB, and these patients had significantly lower proBNP at 6 and 12 months follow up. Despite significant prevalence of RV dysfunction in the cohort ( $>75 \%$ at 6 months), there was no significant difference in HF hospitalizations based on BB use (14\% vs 15\%) and instead a trend towards less deaths in those on BB (6\% vs 15\%). ACEinh/ARB use was likewise common at 6 month (61\%) and these patients had lower pro B-type natriuretic peptide (proBNP) at 6 and 12 months, lower right atrial (RA) pressures ( 9 vs $12 \mathrm{mmHg}, p=0.03$ ), and a significantly lower mortality - a finding which remained significant on multivariate analysis.

\section{Conclusion}

The use of ACEinh/ARB appeared to be associated with subsequent improved survival, lower proBNP and RA pressures. The use of BB post-LVAD appears safe and was associated with a lower proBNP, even in a patient population with a significant prevalence of RV dysfunction.

Keywords: Left ventricular assist device, advanced heart failure management, heart failure hospitalization

Abbreviations: $\mathrm{BB}=$ Beta blockers, $\mathrm{ACEinh} / \mathrm{ARB}=$ Angiotensin converting enzyme inhibitors/Angiotensin receptor blockers, $\mathrm{RV}=$ right ventricle, $\mathrm{RA}=$ right atrium, $L V A D=$ left ventricular assist device, $C H F=$ congestive heart failure, proBNP $=$ proB-type natriuretic peptide, GDMT= goal directed medical therapy, NYHA= New York Heart Association, INTERMACS= Interagency Registry for Mechanically Assisted Circulatory Support, MAP = mean arterial pressure, $\mathrm{LDH}=$ lactate dehydrogenase, LVEDD= left ventricular end diastolic diameter, $\mathrm{Al}=$ aortic insufficiency, MR= mitral regurgitation, $\mathrm{TR}=$ tricuspid regurgitation

\section{Background}

While reverse remodeling and optimal heart failure medical therapy is recognized as an important component in the management of patients with advanced heart failure (1), this goal directed medical therapy (GDMT) is often not given to patients following Left Ventricular Assist Device (LVAD) implantation and its use post-LVAD implantation remains controversial (2). Recipients of mechanical support have advanced heart failure and are likely to have a similar neurohormonal milieu to other advanced heart failure patients $(3,4)$. Furthermore the right side of the heart is unsupported and the addition of the device may lead to worsening of right ventricular (RV) dysfunction following LVAD implantation due to septal shift and increased flow to the RV. Hence these patients may continue to suffer from adverse cardiovascular comorbidities such as ongoing fluid retention leading to heart failure hospitalizations. Patients post implant may therefore potentially derive benefit from angiotensin system and beta blockade which might improve their 
quality of life and reduce hospitalizations and adverse events. Such therapy also results in better blood pressure control hence decreasing the incidence of stroke (5) on LVAD support. Furthermore, neurohormonal antagonists, beta blockers, and aldosterone antagonists all significantly facilitate ventricular reverse remodeling and reduce fibrosis leading to myocardial recovery and subsequent explantation in some cases $(6,7)$. Despite these potential benefits, concerns have been raised about the safety of GDMT, due to possible deleterious effects of beta-blockers on right ventricular $(\mathrm{RV})$ function after LVAD implantation as well concerns regarding their tolerance (8). Particularly given the high morbidity related to both early and late RV dysfunction post LVAD implantation, optimizing medical therapy has becomes a controversial dilemma. Whether beta blocker therapy is beneficial or detrimental for RV dysfunction after LVAD implantation has not been determined. Beneficial effects of beta blockers in VAD patients have preliminarily been suggested in a recent abstract (9), however published data on the potential benefits of beta blockers and other heart failure therapy remains scarce. With the rising cohort of LVAD patients each year (10), there is an increasing need for data to understand the post-implantation optimum medical therapy that will result in the best outcomes. We aimed to determine the effect of heart failure medical therapy on the outcomes and adverse events in patients implanted with an LVAD at a tertiary heart failure center.

\section{Methods}

\section{Study population:}

We performed a retrospective review of consecutive patients implanted with a continuous flow LVAD-HeartMate II(Abbott, Abbott Park, IL) or Heart-Ware (Medtronic, Minneapolis, MN), between January 2012 and December 2015 at a tertiary care facility. Appropriate Institutional Review Board exemption was obtained. Exclusion criteria included patients with their first LVAD placed prior to 2012 with re-implantation in the study period, an LVAD placed elsewhere, or death/transplant within 6 months of implant (as these patients would not have data available for collection at 6 months post implant). Key patient demographics and echocardiographic variables were collected prior to-implant and 6 months after implantation and key laboratory findings were collected pre implant, 6 months, and 12 months post LVAD-implant. Medication use and doses including beta-blocker in metoprolol equivalent, angiotensin converting enzyme inhibitor (ACEinh) or angiotensin receptor blockers (ARBs) in lisinopril equivalent, loop diuretics in bumetanide equivalent, calcium channel blockers in amlodipine equivalent, spironolactone, metolazone, hydralazine and nitrate use before implant, and at 6 and 12 months post-implant were collected. Heart failure and other medication use was at the discretion of the advanced heart failure team based on individual practice pattern and patient tolerance, and were often initiated as early as implant admission or on early outpatient follow-up. Data on mortality and heart failure 
hospitalizations were collected from 6 to18 months post-implant (the 12 month study window). Loss of patients to follow-up or missing follow-up data was expected to be rare, as our facility is the only LVAD center in the area and we are notified when our patients present elsewhere and routinely transfer LVAD patients to our facility.

Echocardiographic (echo) data at 6 months post-implant was collected retrospectively from reports. Echocardiograms were routinely performed at this time frame as per our program protocols, and only echocardiograms performed during outpatient follow up (in compensated state) were included. Assessment of chamber size or function was based on the American Society of Echo guidelines (11). Right atrial pressure was derived through echocardiographic assessment. Not all echo variables were available on all patients due to poor image quality or uninterpretable data and these data points were excluded from the study. Variable that were not available were left as missing from data analysis. Congestive heart failure (CHF) hospitalization was defined as admission secondary to fluid overload with signs and symptoms requiring hospital-based medical treatment with diuretics, occurring between 6-18 months after implantation. Mean arterial pressure was reported based on program protocols using the mean pressure obtained from an automated non-invasive measurement or a Doppler.

Statistical analysis:

Forward and backward conditional multivariate logistic regression analysis was performed using demographic, medication and echocardiography data to identify predictors of hospitalization and mortality. The variables used for the above analysis included age, gender, diabetes, individual medication use, mean arterial pressures, serum creatinine. Significance was defined at $p$-value $\leq 0.05$.

IBM SPSS (version 19.0, SPSS Corp, Chicago, IL, USA) was used for statistical analysis. Qualitative data is presented as frequencies and quantitative data as mean \pm standard deviation. Categorical variables were compared by using Chisquare test, and continuous variables were compared using Student's t-test. Paired t-test was used for numerical variables and McNemar test was used for nominal variables for before and after implantation comparison. Prevalence and percentages in the table represent patients with available and interpretable data for each variable. Microsoft Excel 2013 was used for building charts and figures.

\section{Results}

In total, 138 patients had an LVAD placed and were discharged between January 2012 and December 2015, of which 9 patients underwent LVAD placement twice in the study period and 31 patients were also excluded based on the exclusion criteria (Figure 1). Thus, 98 patients (58 HeartMate II, 40 HeartWare) were identified for inclusion into the study. 


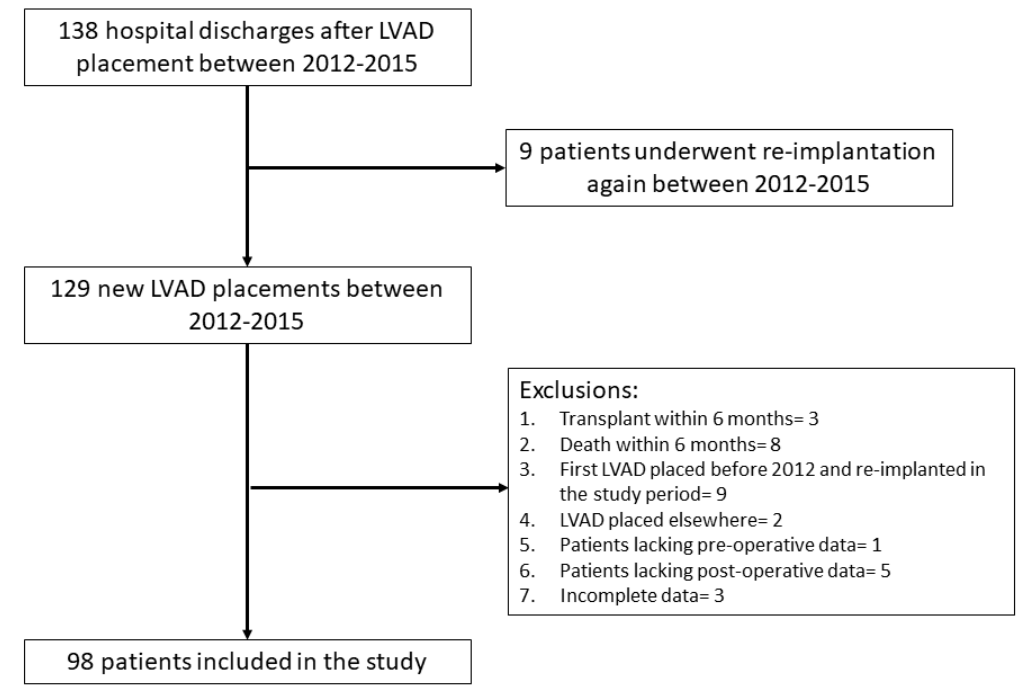

Figure 1. Selection criteria for the study

Paired comparison of individual patients (before and after implant) is summarized in Table 1.

Table 1. Paired-statistic comparison of patients before and 6 months after LVAD implantation

\begin{tabular}{|l|l|l|l|}
\hline & Pre-implant & 6 months & P-value \\
\hline NYHA class 3 \& 4 patients (n) & $98(100 \%)$ & $3(3 \%)$ & 0.01 \\
\hline Creatinine (mg/dL) & $1.36 \pm 0.56$ & $1.36 \pm 0.75$ & 0.79 \\
\hline Albumin(g/dL) & $3.37 \pm 0.49$ & $3.68 \pm 0.51$ & 0.01 \\
\hline Bilirubin (mg/dL) & $1.56 \pm 1.22$ & $1.19 \pm 2.90$ & 0.32 \\
\hline LDH(U/L) & $224 \pm 130.36$ & $225.9 \pm 72.40$ & 0.69 \\
\hline ProBNP (pg/mL) & $4670.86 \pm 3728.55$ & $2538.06 \pm 4052.37$ & 0.01 \\
\hline Greater than moderate AI (n) & $23(31.5 \%)$ & $11(15 \%)$ & 0.02 \\
\hline Greater than moderate MR (n) & $37(40 \%)$ & $20(27 \%)$ & 0.15 \\
\hline Greater than moderate TR (n) & $20(22 \%)$ & $9(12 \%)$ & 0.07 \\
\hline RA pressure (mm Hg) & $12.82+-4.97$ & $11.00+-4.47$ & 0.04 \\
\hline $\begin{array}{l}\text { Greater than moderate RV } \\
\text { enlargement(n) }\end{array}$ & $28(40.6 \%)$ & $37(53.6 \%)$ & 0.16 \\
\hline $\begin{array}{l}\text { Greater than moderate RV } \\
\text { dysfunction (n) }\end{array}$ & $47(64.4 \%)$ & $55(75.3 \%)$ & 0.20 \\
\hline LVEDD $(\mathrm{cm})$ & $7.08+-1.25$ & $6.30+-1.37$ & 0.01 \\
\hline
\end{tabular}

Mean patient age was $57 \pm 14$ years and 79 patients $(81 \%)$ were male. The cause of heart failure was ischemic in 41 patients $(61 \%)$ and 69 patients $(70 \%)$ were implanted as destination therapy. On LVAD support, the mean arterial pressure 
was $89 \pm 13 \mathrm{mmHg}$ at 6 months and $85 \pm 12 \mathrm{mmHg}$ at 12 months. At 6 and 12 months, only $3 \%$ and $4 \%$ of patients respectively were New York Heart

Association Class III and IV. There was a trend towards more RV dilation and dysfunction on the 6 month echocardiogram compared to baseline, although this did not meet statistical significance. A total of $14(14 \%)$ patients were hospitalized with $\mathrm{CHF}$ exacerbation and 8 patients (8\%) died during the 6-18 months of follow up.

The frequency of use of diuretics and heart failure medications as well as the equivalent doses used pre implant, and at 6 and 12 months post-LVAD is shown in Table 2.

Table 2: Use of GDMT, diuretics, and calcium-channel blockers (CCB) prior to and post LVAD implant.

\begin{tabular}{|l|l|l|l|}
\hline Medications & Pre-implant & $\mathbf{6}$ months & 12 months \\
\hline Metolazone $(\mathrm{n})$ & $22(23.2 \%)$ & $9(9.2 \%)$ & $11(12.9 \%)$ \\
\hline Spironolactone (n) & $62(63.9 \%)$ & $53(54.1 \%)$ & $40(47.6 \%)$ \\
\hline Beta blocker (n) & $76(77.6 \%)$ & $72(73.5 \%)$ & $71(84.5 \%)$ \\
\hline ACEinh/ARB (n) & $53(54.1 \%)$ & $59(60.8 \%)$ & $55(66.3 \%)$ \\
\hline Loop Diuretic (n) & $88(90.7 \%)$ & $56(58.1 \%)$ & $47(56 \%)$ \\
\hline Nitrates (n) & $11(11.3 \%)$ & $6(6.1 \%)$ & $5(6 \%)$ \\
\hline Hydralazine (n) & $10(10.3 \%)$ & $35(36.1 \%)$ & $35(41.7 \%)$ \\
\hline CCB (n) & $1(1 \%)$ & $14(14.3 \%)$ & $13(15.7 \%)$ \\
\hline Aspirin (n) & $77(78.6 \%)$ & $91(92.9 \%)$ & $75(89.3 \%)$ \\
\hline Bumex equivalent (mg) & $3.06+-2.04$ & $1.26+-1.77$ & $1.41+-2.01$ \\
\hline Metoprolol equivalent (mg) & $64.05+-66.93$ & $81.66+-104.53$ & $103.07+-122.30$ \\
\hline Lisinopril equivalent (mg) & $6.53+-11.76$ & $16.40+-37.27$ & $14.88+-38.20$ \\
\hline
\end{tabular}

Figure 2 shows the percentage of patients on various heart failure and antihypertensive medications before and after implantation. Figure 3 depicts the number of medications prescribed to patients during the same time period (from 0 to $\geq 4$ medications). While the use of loop diuretics decreased from pre-implant to post-implant, more than $50 \%$ of patients continued to require loop diuretics at 6 
and 12 months post implant. Thiazide diuretic remained similar pre and post implant. The use of beta-blockers, ACEinh/ARBs, and spironolactone, Hydralazine and calcium channel blockers was relatively high post-LVAD at our center. Figure 4 describes the trend of beta-blocker, ACEinh/ARB and loop diuretic dosage prescription before and after implantation. The rate of pre-LVAD medical therapy use was similar compared to prior advanced heart failure cohorts.

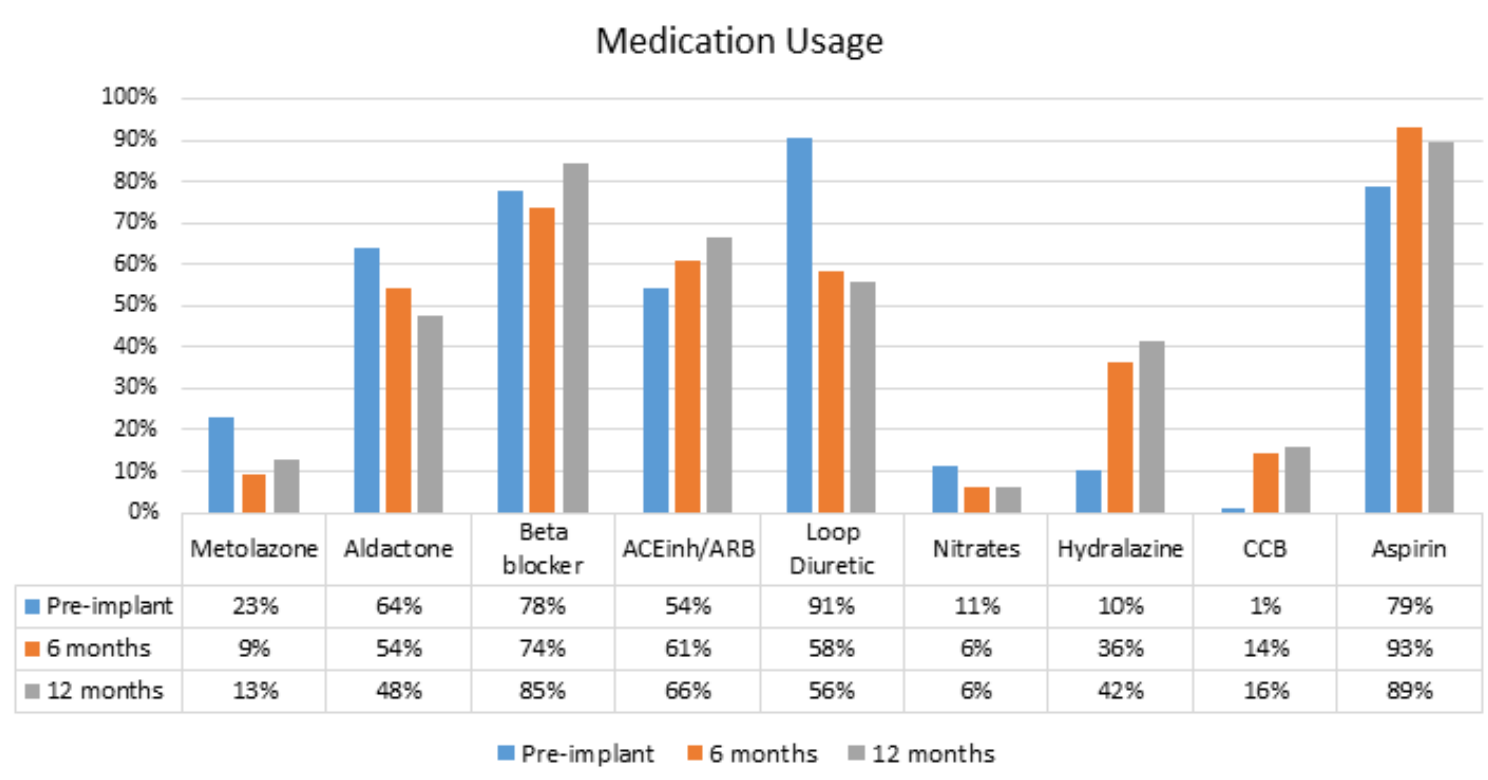

Figure 2: Use of GDMT, diuretics, and CCB prior to and post LVAD implant

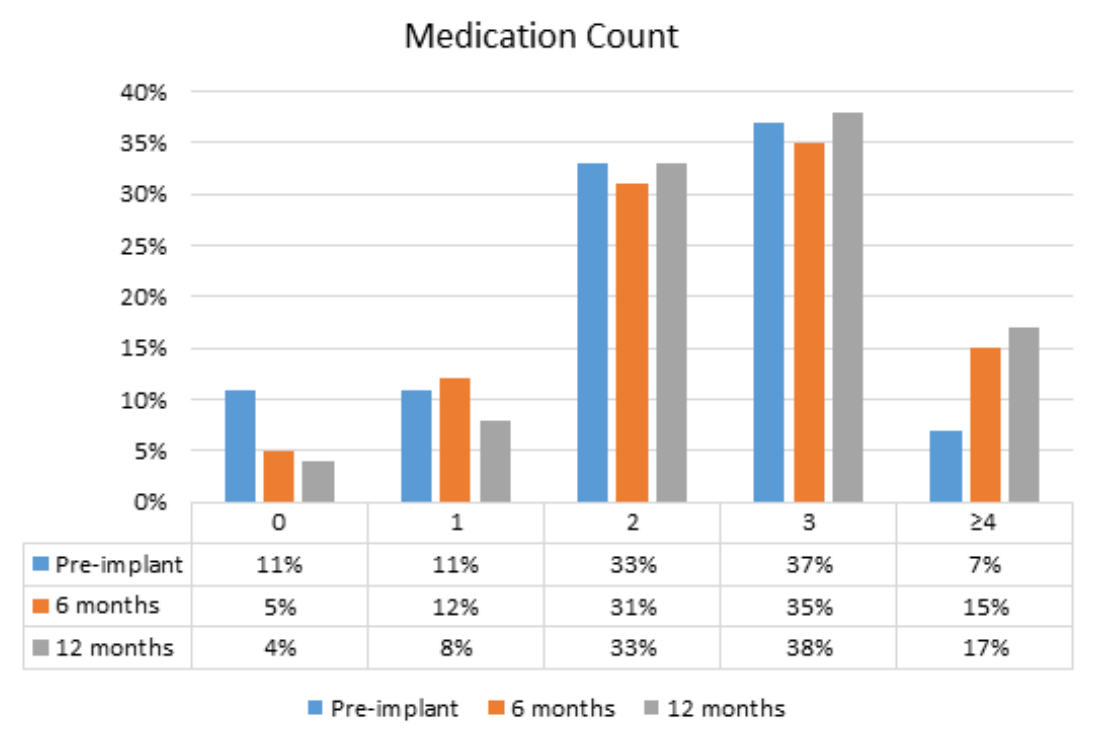

Figure 3: Number of GDMT meds and CCB prescribed prior to and post LVAD implantation 


\section{Trend of Medication Doses}

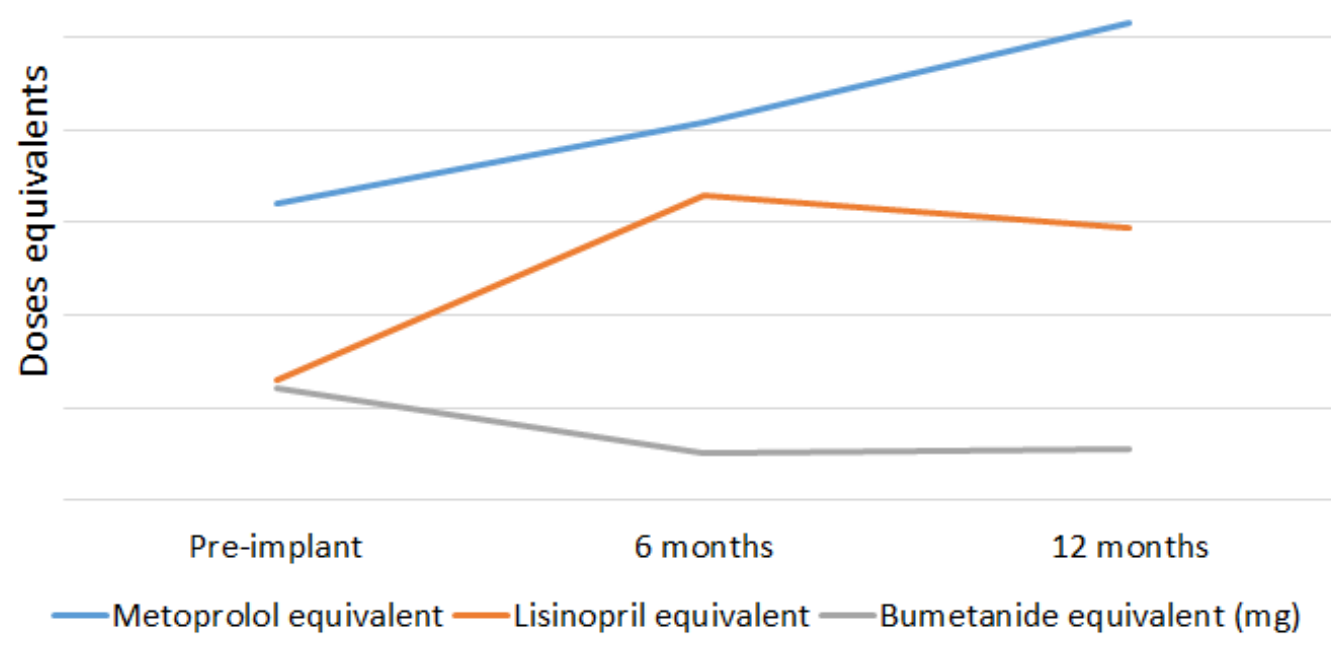

Figure 4: Trend of medication doses pre and post-implant

Table 3 depicts the demographic, laboratory, echocardiographic and outcome data of patients on and off beta blockers, ACEinh/ARB, and spironolactone. Patients on BBs were younger and more likely to be men and patients on ACEinh/ARB were younger and had better renal function, though the key laboratory and echo characteristics were otherwise similar between those on and off these therapies. Blood pressures at 6 and 12 months were not significantly different among patients on versus off medical therapy (data not shown), as therapy was often titrated to achieve a desired blood pressure.

At 6 months post-implantation, 72 patients (73\%) (44 HeartMate II, 28 Heart-Ware) were on beta-blockers with a daily metoprolol equivalent dose of $82 \mathrm{mg}( \pm 105)$ mg. Beta-blocker use was similarly distributed among patients irrespective of the severity of the underlying RV dilation or dysfunction. Beta blockers at 6 months were used in $74 \%, 68 \%$, and $78 \%$ of patients with normal/mild, moderate, or greater than moderate degree of RV dysfunction respectively based on the 6 month echo. Likewise, beta blockers were used in $82 \%, 64 \%$ and $71 \%$ of patients with normal/mild, moderate, or greater than moderate degree of RV dilation respectively based on the 6 month echo. Despite a significant prevalence of RV dilation and dysfunction in the cohort, there was no significant difference in heart failure hospitalizations with BB use (14\% vs 15\%) and instead a trend towards less deaths in those on BB (6\% vs 15\%). Patients on beta-blockers also had significantly lower proBNP at 6 months $(1915 \pm 2860$ vs $4217 \pm 5983 \mathrm{pg} / \mathrm{mL}, \mathrm{p}=$ $0.01)$ and a trend towards lower BNP at 12 months ( $2260 \pm 4538$ vs $5188 \pm 10590$ $\mathrm{pg} / \mathrm{mL}, \mathrm{p}=0.08)$. 
The VAD Journal: The journal of mechanical assisted circulation and heart failure

Table 3 A: Comparison of variables on and off GDMT medications, all variables correlate with 6 month data unless specified

\begin{tabular}{|c|c|c|c|c|c|c|}
\hline & \multicolumn{3}{|c|}{ Beta-Blocker therapy } & \multicolumn{3}{|c|}{ ACEinh/ARB therapy } \\
\hline & On therapy & Off therapy & $\begin{array}{l}\mathrm{P} \text { - } \\
\text { value }\end{array}$ & $\begin{array}{l}\text { On } \\
\text { therapy }\end{array}$ & $\begin{array}{l}\text { Off } \\
\text { therapy }\end{array}$ & $\begin{array}{l}\mathrm{P}- \\
\text { value }\end{array}$ \\
\hline Age (years) & $55 \pm 14$ & $63 \pm 11$ & 0.02 & $54 \pm 14$ & $62 \pm 12$ & 0.04 \\
\hline Males (n) & $62(86 \%)$ & $17(65 \%)$ & 0.02 & $47(80 \%)$ & $32(84 \%)$ & 0.57 \\
\hline $\begin{array}{l}\text { Ischemic } \\
\text { cardiomyopathy (n) }\end{array}$ & $63 \%$ & $62 \%$ & 0.93 & $63 \%$ & $63 \%$ & 0.96 \\
\hline $\mathrm{MAP}(\mathrm{mm} \mathrm{Hg})$ & $\begin{array}{l}87.69 \pm \\
13.8\end{array}$ & $90.81 \pm 11.8$ & 0.31 & $\begin{array}{l}88.31 \pm \\
13.4\end{array}$ & $\begin{array}{l}89.08 \pm \\
13.4\end{array}$ & 0.78 \\
\hline Creatinine $(\mathrm{mg} / \mathrm{dL})$ & $1.4 \pm 0.7$ & $1.4 \pm 0.8$ & 0.78 & $1.1 \pm 0.3$ & $1.7 \pm 1.1$ & 0.01 \\
\hline Bilirubin $(\mathrm{mg} / \mathrm{dL})$ & $0.9 \pm 0.4$ & $1.1 \pm 1.2$ & 0.25 & $1.2 \pm 3.7$ & $1.1 \pm 1.0$ & 0.91 \\
\hline $\mathrm{LDH}(\mathrm{U} / \mathrm{L})$ & $225 \pm 78$ & $229 \pm 53$ & 0.79 & $221 \pm 78$ & $233 \pm 63$ & 0.43 \\
\hline Albumin (g/dL) & $3.7 \pm 0.5$ & $3.5 \pm 0.6$ & 0.08 & $3.8 \pm 0.4$ & $3.4 \pm 0.6$ & 0.01 \\
\hline $\begin{array}{l}\text { proBNP (at } 6 \text { months) } \\
\mathrm{pg} / \mathrm{ml}\end{array}$ & $\begin{array}{l}1915 \pm \\
2860\end{array}$ & $4217 \pm 5983$ & 0.01 & $\begin{array}{l}1186 \pm \\
1106\end{array}$ & $\begin{array}{l}4715 \pm \\
5784\end{array}$ & 0.01 \\
\hline $\begin{array}{l}\text { proBNP (at } 12 \\
\text { months) } \mathrm{pg} / \mathrm{ml}\end{array}$ & $\begin{array}{l}2260 \pm \\
4538 \\
\end{array}$ & $\begin{array}{l}5188 \pm \\
10590 \\
\end{array}$ & 0.08 & $\begin{array}{l}1356 \pm \\
1280\end{array}$ & $\begin{array}{l}5590 \pm \\
10015\end{array}$ & 0.01 \\
\hline LVEDD (cm.) & $6.5 \pm 1.4$ & $5.7 \pm 1.2$ & 0.03 & $6.3 \pm 1.5$ & $6.3 \pm 1.0$ & 0.90 \\
\hline RA pressure $(\mathrm{mm} \mathrm{Hg})$ & $10 \pm 4$ & $11 \pm 4$ & 0.67 & $9 \pm 3$ & $12 \pm 5$ & 0.03 \\
\hline $\begin{array}{l}\text { Greater than } \\
\text { moderate Al (n) }\end{array}$ & $8(14 \%)$ & $3(16 \%)$ & 0.85 & $4(6 \%)$ & $7(18 \%)$ & 0.06 \\
\hline $\begin{array}{l}\text { Greater than } \\
\text { moderate MR (n) }\end{array}$ & $14(26 \%)$ & $6(32 \%)$ & 0.63 & $9(21 \%)$ & $10(35 \%)$ & 0.20 \\
\hline $\begin{array}{l}\text { Greater than } \\
\text { moderate TR (n) }\end{array}$ & $6(11 \%)$ & $3(15 \%)$ & 0.64 & $5(11 \%)$ & $3(11 \%)$ & 0.97 \\
\hline $\begin{array}{l}\text { Greater than } \\
\text { moderate } R V \text { dilation } \\
\text { (n) }\end{array}$ & 10 (71.4\%) & $4(28.6 \%)$ & 0.28 & $8(17 \%)$ & $6(22 \%)$ & 0.71 \\
\hline $\begin{array}{l}\text { Greater than } \\
\text { moderate RV } \\
\text { dysfunction (n) }\end{array}$ & $28(77.8 \%)$ & $8(22.2 \%)$ & 0.75 & $22(49 \%)$ & $14(50 \%)$ & 0.92 \\
\hline $\begin{array}{l}\text { CHF hospitalization } \\
\text { (n) }\end{array}$ & $10(14 \%)$ & $4(15 \%)$ & 0.85 & $8(14 \%)$ & $6(16 \%)$ & 0.76 \\
\hline Death $(n)$ & $4(6 \%)$ & $4(15 \%)$ & 0.12 & $1(2 \%)$ & $7(18 \%)$ & 0.01 \\
\hline
\end{tabular}


Table 3 B: Comparison of variables on and off other spironolactone, all variables correlate with 6 month data unless specified

\begin{tabular}{|l|l|l|l|}
\hline & $\begin{array}{l}\text { On spironolactone } \\
(\mathrm{n}=53)\end{array}$ & $\begin{array}{l}\text { Off spironolactone } \\
(\mathrm{n}=45)\end{array}$ & P-value \\
\hline Age (years) & $53 \pm 14$ & $63 \pm 12$ & 0.01 \\
\hline Males $(\mathrm{n})$ & $41(77 \%)$ & $38(84 \%)$ & 0.37 \\
\hline Ischemic cardiomyopathy $(\mathrm{n})$ & $49 \%$ & $78 \%$ & 0.03 \\
\hline MAP $(\mathrm{mm} \mathrm{Hg})$ & $87.13 \pm 13.6$ & $90.13 \pm 13.0$ & 0.27 \\
\hline Creatinine $(\mathrm{mg} / \mathrm{dL})$ & $1.1 \pm 0.4$ & $1.5 \pm 1.0$ & 0.01 \\
\hline Bilirubin $(\mathrm{mg} / \mathrm{dL})$ & $1.4 \pm 3.8$ & $1.0 \pm 1.0$ & 0.49 \\
\hline LDH (U/L) & $216 \pm 76$ & $239 \pm 66$ & 0.12 \\
\hline Albumin $(\mathrm{g} / \mathrm{dL})$ & $3.8 \pm 0.5$ & $3.6 \pm 0.5$ & 0.09 \\
\hline proBNP (at 6 months) pg/ml & $1813 \pm 3058$ & $3431 \pm 4907$ & 0.05 \\
\hline proBNP (at 12 months) pg/ml & $1419 \pm 1276$ & $4635 \pm 9116$ & 0.02 \\
\hline LVEDD (cm.) & $6.3 \pm 1.6$ & $6.1 \pm 1.1$ & 0.60 \\
\hline RA pressure (mm Hg) & $10 \pm 4$ & $11 \pm 5$ & 0.20 \\
\hline Greater than moderate AI (n) & $4(10 \%)$ & $7(21 \%)$ & 0.14 \\
\hline Greater than moderate MR $(\mathrm{n})$ & $13(33 \%)$ & $7(21 \%)$ & 0.28 \\
\hline Greater than moderate TR $(\mathrm{n})$ & $5(12 \%)$ & $4(13 \%)$ & 0.93 \\
\hline $\begin{array}{l}\text { Greater than moderate RV } \\
\text { dilation }(\mathrm{n})\end{array}$ & $7(18 \%)$ & $7(22 \%)$ & 0.71 \\
\hline $\begin{array}{l}\text { Greater than moderate RV } \\
\text { dysfunction }(\mathrm{n})\end{array}$ & $19(45 \%)$ & $17(53 \%)$ & 0.50 \\
\hline CHF hospitalization $(\mathrm{n})$ & $7(13 \%)$ & $7(16 \%)$ & 0.74 \\
\hline Death $(\mathrm{n})$ & $3(6 \%)$ & $5(11 \%)$ & 0.32 \\
\hline
\end{tabular}

At 6 months post implantation, 59 patients (60\%) (32 HeartMate II, 27 Heart-Ware) were on an ACE inhibitor or ARB, with an average lisinopril equivalent dose of 16 $\pm 37 \mathrm{mg} /$ day. Although patients on an ACE inhibitor had worse NYHA Class prior to LVAD implantation, they had significantly lower proBNPs at 6 and 12 months following LVAD implant as well as a lower RA pressure compared to those not on an ACE inhibitor. Over the 6-18 month follow-up period, the mortality rate was $1 / 60$ (2\%) among patients on ACEinh/ARB and 7/38 (18\%) among patients not on ACEinh/ARB $(p=0.01)$. The beneficial effect on survival remained significant in multivariate analyses accounting for age, gender, renal function, and concomitant medication use (Odds ratio: 0.07, Confidence Interval 0.009-0.649, $p=0.018$ ).

Key variables for patients with and without a CHF hospitalization between 6-18 months after LVAD implantation are shown in Table 4. Patient who experienced a hospitalization were more likely to be on diuretic at 6 months $(p=0.021)$ and were on a higherbumetanideequivalent dose than the non-hospitalized group $(2.24 \pm 2.2$ vs $1.01 \pm 1.5 \mathrm{mg}, \mathrm{p}=0.002$ ). In multivariate analysis including age, gender, renal function, and medication use, diuretic use at 6 months remained a predictor of subsequent CHF hospitalization (Odds ratio: 5.7, Confidence Interval 1.2-27.2, $p=$ 
0.029). When echo parameters were included in the multivariate model, only RA pressure of $\geq$ to $12.5 \mathrm{mmHg}$ at 6 months remained predictive of subsequent CHF hospitalizations (Odds ratio: 1.228, 95\% Confidence Interval 1.040-1.451, $\mathrm{p}=$ 0.01).

Table 4: Six months patient characteristics and association with subsequent heart failure hospitalization over the following 12 months

\begin{tabular}{|l|l|l|l|}
\hline \multirow{2}{*}{ At 6 months } & \multicolumn{2}{c|}{ CHF hospitalization } & \multirow{2}{*}{ P value } \\
\cline { 2 - 3 } & Yes & No & \\
\hline On metolazone(n) & $4(23 \%)$ & $5(6.1 \%)$ & 0.02 \\
\hline On diuretic (n) & $14(82.3 \%)$ & $42(51.8 \%)$ & 0.02 \\
\hline NYHA class 3 or 4 (n) & $2(11.7 \%)$ & $1(1.2 \%)$ & 0.02 \\
\hline MAP (mm Hg) & $86.33 \pm 6.55$ & $87.00 \pm 13.37$ & 0.865 \\
\hline Bumex equivalent (mg) & $2.44 \pm 2.23$ & $1.01 \pm 1.56$ & 0.01 \\
\hline RA pressure (mm Hg) & $13.57 \pm 4.75$ & $9.43 \pm 3.78$ & 0.01 \\
\hline Greater than moderate RV dilation (n) & $8(62 \%)$ & $31(50 \%)$ & 0.44 \\
\hline Greater than moderate RV dysfunction (n) & $10(77 \%)$ & $49(74 \%)$ & 0.83 \\
\hline Greater than moderate AI (n) & $3(25 \%)$ & $8(13 \%)$ & 0.25 \\
\hline Greater than moderate MR (n) & $3(27 \%)$ & $17(27 \%)$ & 0.99 \\
\hline Greater than moderate TR (n) & $0(0 \%)$ & $9(14 \%)$ & 0.15 \\
\hline LVEDD (cm.) & $6.40 \pm 0.90$ & $6.25 \pm 1.39$ & 0.72 \\
\hline Aortic valve opening (n) & $4(36 \%)$ & $56(47 \%)$ & 0.50 \\
\hline
\end{tabular}

There were 7 admissions for implanted defibrillator discharge but BB use was not associated with any significant difference $(p=0.09$ at 6 months and $p=0.23$ at 12 months). Death between 6-18 months in our cohort occurred in 8 patients. Causes included progressive renal failure/multi-organ failure (4 patients), withdrawal of care/hospice (3 patients), PEA and presumed bacteremia (1 patient).

\section{Discussion}

The past decade has seen LVAD implantation become mainstream in the management of advanced heart failure through significant improvement in the reliability, safety and longevity of the pumps. With increasing demand and unchanged availability of transplant-eligible hearts, LVAD implantation can be expected to increase with time. In the 9 years of Interagency Registry for 
Mechanically Assisted Circulatory Support (INTERMACS) Registry, more than 15,000 patients have been implanted with an LVAD in 158 participating institutions(10). However, there is no clear understanding and a surprising lack of evidence about the role of heart failure therapy post LVAD implantation(2). Among our cohort, the use of heart failure therapy post LVAD implantation appeared safe and beneficial, which has important clinical implications for the medical management of this growing group of patients.

\section{Angiotensin inhibitors post LVAD}

Here, we show, for the first time, that patients receiving an ACE inhibitor (despite being in a worse NYHA Class prior to LVAD implantation in our series) had significantly lower proBNPs at 6 monthsand 12 monthsfollowing LVAD implant and better survival after LVAD implantation both in univariate and multivariate analyses. Patients on an ACE inhibitor or ARB also had a subsequent lower RA pressure compared to those not on an ACEinh/ARB suggesting a potential beneficial effect on RV function.

There are several potential mechanisms to explain the beneficial clinical effects of angiotensin system blockade post implantation. Use of ACEinh/ARB have been reported to reverse myocardial remodeling(12) and arteriovenous malformation related gastrointestinal bleeding(13) among post-LVAD patients, however efficacy and mortality data have been lacking so far. In a retrospective study of 131 patients(13), use of ACEinh/ARB was an independent factor in reducing the risk of significant gastrointestinal bleeding, including arteriovenous malformation associated bleeding. In a study of myocardial biopsy samples pre and post-LVAD implantation, Klotz et al reported low myocardial collagen content and stiffness post-LVAD implantation in patients prescribed angiotensin system blockers, possibly suggesting reverse remodeling in these patients(12). The findings of the present study suggest that these or other mechanisms may have clinical utility through improved outcomes including survival. These finding will need to be validated however in larger patient cohorts, such as INTERMACS.

\section{Beta blockade post LVAD}

Our fairly well characterized cohort also suggested that beta blockers are potentially beneficial post LVAD implantation. Despite a population with a significant prevalence of RV dilation and dysfunction, patients on beta-blockers had a significantly lower proBNP 6 months after LVAD implantation and a trend towards a lower BNP at 12 months. Beta blockers furthermore appear safe as there was no significant difference in the frequency of heart failure hospitalization with beta blocker use and a trend towards lower mortality in those on beta blockers. 
Beta-blockers are widely used for left ventricular failure but their role in right ventricular failure (and therefore their role post LVAD implantation) remains unestablished with even a suggestion of a negative effect(8) Although the possible negative effect is a widely held belief, the evidence for it is extremely sparse. Pulmonary arterial hypertension is considered a relative contraindication for betablocker use due to concerns of a possible negative effect on hemodynamics and exercise capacity. However this is only based on a small study of 10 patients with porto-pulmonary hypertension in which withdrawal of propranolol was associated with improved exercise tolerance and on one case report (14-16). Furthermore more recent literature in patients with pulmonary hypertension and congenital heart disease suggests otherwise with improvements in RV re-modelling(17) and RV end-diastolic volumes(18) with beta blocker therapy, and such therapy having no deleterious effect on exercise capacity or mortality $(18,19)$. Beta blockers have been shown to improve RV function and prevent myocardial re-modelling in animal models of pulmonary hypertension $(17,20)$ as well as to reverse the characteristic 'molecular signature' of RV failure(21). In humans a small single arm study of beta blockers in patients post correction of transposition of the great arteries showed improvements in symptoms, quality of life and RV ejection fraction(22).

Furthermore more recently, a prospective cohort study of $94 \mathrm{PAH}$ patients found no increase in adverse clinical or hemodynamic consequences in the 285 patients on beta blockers for other cardiac co-morbidities(19). However we continue to lack large prospective trials to prove the role of beta-blockers in RV failure(23). Our data certainly suggests no increase in adverse events with beta blocker use on clinical right ventricular function with potential beneficial clinical effects.

Another potential mechanism of beta blocker benefit is through arrhythmia prevention. The risk of ventricular arrhythmia is significant after LVAD placement and arrhythmia can worsen RV function. Early beta-blockade is certainly suggested in patients with pre-or post-LVAD history of arrhythmias(24), and one mechanism of the benefit can be through RV preservation(25).

\section{Myocardial Recovery}

Mechanical unloading with an LVAD can lead to sufficient reverse remodeling and improvement in myocardial function to allow explantation of the device and leave the patient with a good quality of life. However the rate at which this occurs has been highly variable and it is likely that neuro-hormonal antagonists, beta blockers, and aldosterone antagonists all significantly facilitate ventricular reverse remodeling and reduce fibrosis leading to myocardial recovery and subsequent explantation in a higher proportion of cases after LVAD support. LVAD patients continue to have pathological re-modelling and increase in myocardial stiffness(26). Two prospective studies $(6,7)$ have suggested that aggressive uptitration of reverse remodeling heart failure therapy including high dose ACEinh and beta-blockers is associated with improvement in severe heart failure from non- 
ischemic cardiomyopathy and successful device explantation in patients through reversal of the pathological re-modelling. The demonstration that angiotensin system inhibitors and beta blockers appear safe in LVAD recipients may allow for their greater use and therefore greater possibility of eventual explantation. Prior to LVAD implantation, patients usually become intolerant to these therapies due to hypotension and renal failure (from the low cardiac output), but the improved flow, better blood pressure and improved renal function provided by the LVAD may allow up-titration of these drugs to very high doses thus making the LVAD a platform for myocardial recovery.

The trend towards a greater degree of RV dilation and dysfunction on the postVAD echocardiograms at 6 months is of unclear significance. Possible explanations include an increase in venous return due to improved left sided cardiac output and potential effects of LV suction on the ventricular septum.

\section{Clinical Implications}

Similar to our findings, a recent study from the INTERMACS data(2) noted an increase in prescription of ACEinh, ARBs and beta-blockers 3 months and 6 months post-implantation. While the use of loop diuretics declined after implantation in the INTERMACS cohort, the number still remained considerably high ( $>55 \%$ patients). The study also reported highest beta-blocker use in younger patients which is similar to our present study. These findings are similar to the practice pattern in our hospital, making our results potentially applicable to larger populations. Not all patients in the INTERMACS cohort were prescribed GDMT post-implant and this could be indicative of individual patient intolerance to these medications but also likely signify the uncertainty and lack of guidelines. Currently, the International Society for Heart and Lung Transplantation (ISHLT) recommends utilization of heart failure medications (ACEinh, ARBs and beta-blockers) for blood pressure or tachyarrhythmia management(27) but no recommendation has been made for their continued utilization in LVAD patients for management of heart failure per se. ACE/ARB and beta blockers will also lower blood pressure in LVAD patients which will have a secondary beneficial effect by lowering the stroke risk(5). Our current results highlight a potential beneficial role for these therapies above and beyond blood pressure and arrhythmia prevention by demonstrating both safety and potential efficacy in our cohort.

We also found that risk of heart failure hospitalization during follow up was associated with diuretic use and with higher RA pressure(table 4), suggesting a possible association with "late RV failure". These findings may have important implications for optimizing medical therapy post LVAD implantation and for identifying patients at highest risks for adverse events. 


\section{Limitations}

The limitations of the study include the retrospective design and single facility. The study was underpowered to perform significant subset analysis or present a prediction model. This study aimed at understanding the outpatient practice pattern in LVAD implanted patients and evaluating the safety of continued prescription of beta-blockers and other heart failure medical therapies. Also the difference in prescription of medications (ACEinh and diuretics) in subgroup analysis for predictors may be confounded by individual intolerance and not clearly indicate efficacy. Medication use at the 6 month time-point only was used for statistical analysis and the use or duration of heart failure therapy prior to or after the 6 month time frame may have varied among patients. The position of the ventricular septum was not addressed on all studies.

\section{Conclusion}

In conclusion this study presents a well characterized cohort of advanced heart failure patients post LVAD implantation, with several key findings. We demonstrate that the use of angiotensin system inhibitors appeared to be associated with lower pro-BNP, RA pressure, and most importantly improved survival. We also demonstrate that beta blocker therapy appears safe, including in patients with significant right ventricular dysfunction, and may be beneficial in patients post LVAD implantation by being associated with a lower pro-BNP. The use of betablocker and angiotensin system inhibitors in LVAD patients need further investigation, however, this study provides evidence to support their use post LVAD implantation. In general, these drugs may not be used as prolifically as they should be, most likely due to the lack of evidence in this patient population. The current study highlights that the risks of heart failure therapies may be overexaggerated while the benefits may be underappreciated. 


\section{References}

1. Hunt SA, Abraham WT, Chin MH et al. 2009 focused update incorporated into the ACC/AHA 2005 Guidelines for the Diagnosis and Management of Heart Failure in Adults: a report of the American College of Cardiology Foundation/American Heart Association Task Force on Practice Guidelines: developed in collaboration with the International Society for Heart and Lung Transplantation. Circulation 2009;119:e391-479.

2. Khazanie P, Hammill BG, Patel CB et al. Use of Heart Failure Medical Therapies Among Patients With Left Ventricular Assist Devices: Insights From INTERMACS. Journal of cardiac failure 2016;22:672-9.

3. Patel SR, Saeed O, Murthy S et al. Combining neurohormonal blockade with continuous-flow left ventricular assist device support for myocardial recovery: a single-arm prospective study. The Journal of heart and lung transplantation : the official publication of the International Society for Heart Transplantation 2013;32:305-12.

4. Ahmad T, Wang T, O'Brien EC et al. Effects of left ventricular assist device support on biomarkers of cardiovascular stress, fibrosis, fluid homeostasis, inflammation, and renal injury. JACC Heart failure 2015;3:30-9.

5. Teuteberg JJ, Slaughter MS, Rogers JG et al. The HVAD Left Ventricular Assist Device: Risk Factors for Neurological Events and Risk Mitigation Strategies. JACC Heart failure 2015;3:818-28.

6. Birks EJ, George RS, Hedger M et al. Reversal of severe heart failure with a continuous-flow left ventricular assist device and pharmacological therapy: a prospective study. Circulation 2011;123:381-90.

7. Birks EJ, Tansley PD, Hardy $\mathrm{J}$ et al. Left ventricular assist device and drug therapy for the reversal of heart failure. The New England journal of medicine 2006;355:1873-84.

8. Argiriou M, Kolokotron SM, Sakellaridis T et al. Right heart failure post left ventricular assist device implantation. Journal of Thoracic Disease 2014;6:S52-9.

9. Yin M, Ko Y-A, Pekarek A et al. B-Blockers Improves Overall Survival during Support with Continuous-Flow Left Ventricular Assist Device. Journal of cardiac failure 2016;22:S21.

10. Kirklin JK, Naftel DC, Pagani FD et al. Seventh INTERMACS annual report: 15,000 patients and counting. The Journal of heart and lung transplantation : the official publication of the International Society for Heart Transplantation 2015;34:1495-504.

11. Zoghbi WA, Adams D, Bonow RO et al. Recommendations for Noninvasive Evaluation of Native Valvular Regurgitation: A Report from the American Society of Echocardiography Developed in Collaboration with the Society for Cardiovascular Magnetic Resonance. Journal of the American Society of Echocardiography : official publication of the American Society of Echocardiography 2017;30:303-371.

12. Klotz S, Danser AH, Foronjy RF et al. The impact of angiotensin-converting enzyme inhibitor therapy on the extracellular collagen matrix during left ventricular assist device support in patients with end-stage heart failure. Journal of the American College of Cardiology 2007;49:1166-74.

13. Houston BA, Schneider AL, Vaishnav J et al. Angiotensin II antagonism is associated with reduced risk for gastrointestinal bleeding caused by 
arteriovenous malformations in patients with left ventricular assist devices. The Journal of heart and lung transplantation : the official publication of the International Society for Heart Transplantation 2017;36:380-385.

14. Provencher S, Herve $P$, Jais $X$ et al. Deleterious effects of beta-blockers on exercise capacity and hemodynamics in patients with portopulmonary hypertension. Gastroenterology 2006;130:120-6.

15. Farha S, Lundgrin EL, Erzurum SC. Novel therapeutic approaches to preserve the right ventricle. Current heart failure reports 2013;10:12-7.

16. Peacock A, Ross K. Pulmonary hypertension: a contraindication to the use of \{beta\}-adrenoceptor blocking agents. Thorax 2010;65:454-5.

17. Bogaard HJ, Natarajan R, Mizuno S et al. Adrenergic receptor blockade reverses right heart remodeling and dysfunction in pulmonary hypertensive rats. American journal of respiratory and critical care medicine 2010;182:652-60.

18. Giardini A, Lovato L, Donti A et al. A pilot study on the effects of carvedilol on right ventricular remodelling and exercise tolerance in patients with systemic right ventricle. International journal of cardiology 2007;114:241-6.

19. So PP, Davies RA, Chandy $G$ et al. Usefulness of beta-blocker therapy and outcomes in patients with pulmonary arterial hypertension. The American journal of cardiology 2012;109:1504-9.

20. de Man FS, Handoko ML, van Ballegoij JJ et al. Bisoprolol delays progression towards right heart failure in experimental pulmonary hypertension. Circulation Heart failure 2012;5:97-105.

21. Drake JI, Bogaard HJ, Mizuno S et al. Molecular signature of a right heart failure program in chronic severe pulmonary hypertension. American journal of respiratory cell and molecular biology 2011;45:1239-47.

22. Bouallal R, Godart F, Francart C, Richard A, Foucher-Hossein C, Lions C. Interest of beta-blockers in patients with right ventricular systemic dysfunction. Cardiology in the young 2010;20:615-9.

23. Winter MM, Bouma BJ, Groenink M et al. Latest insights in therapeutic options for systemic right ventricular failure: a comparison with left ventricular failure. Heart (British Cardiac Society) 2009;95:960-3.

24. Estep JD, Trachtenberg BH, Loza LP, Bruckner BA. Continuous flow left ventricular assist devices: shared care goals of monitoring and treating patients. Methodist DeBakey cardiovascular journal 2015;11:33-44.

25. Refaat M, Chemaly E, Lebeche D, Gwathmey JK, Hajjar RJ. Ventricular arrhythmias after left ventricular assist device implantation. Pacing and clinical electrophysiology : PACE 2008;31:1246-52.

26. Klotz S, Foronjy RF, Dickstein ML et al. Mechanical unloading during left ventricular assist device support increases left ventricular collagen crosslinking and myocardial stiffness. Circulation 2005;112:364-74.

27. Feldman D, Pamboukian SV, Teuteberg JJ et al. The 2013 International Society for Heart and Lung Transplantation Guidelines for mechanical circulatory support: executive summary. The Journal of heart and lung transplantation : the official publication of the International Society for Heart Transplantation 2013;32:157-87. 